\title{
DOSSIÊ: FORÇAȘ ARMADAS E SEGURANÇA PÚBLICA NA AMÉRICA LATINA
}

\section{A INTERVENÇÃO FEDERAL E A RESPONSABILIDADE DA SEGURANÇA PÚBLICA NA BAIIA DE GUANABARA}

\section{LARISSA NOÉ GONÇALVES MIRANDA}

Mestranda no Programa de Pós-graduação em Estudos Marítimos da Escola de Guerra Naval (PPGEM/EGN). Pós-graduanda em Especialização em Ordem Jurídica e Ministério Público pela Fundação Escola Superior do Ministério Público do Estado do Rio de Janeiro (FEMPERJ). Bacharel em Direito pela Universidade Federal do Rio de Janeiro.

\section{RESUMO}

Este estudo tem por escopo analisar os decretos de operações de garantia da lei e da ordem e de intervenção federal no Rio de Janeiro, além de verificar se a Marinha do Brasil deve agir sozinha no que diz respeito à segurança pública na Baía de Guanabara e nos portos. Para tanto, indagou-se sobre o aparato normativo legal e infralegal sobre a matéria, passando por diferenciar intervenção federal de garantia da lei e da ordem, tratando dos planos previstos no MD33-M-10 e do plano de intervenção federal para entender se a Marinha do Brasil possui poder de polícia para tanto ou se trata, exclusivamente, de uma Força Armada para atuar de forma cooperativa com os órgãos de segurança. Entendeu-se no estudo que a competência da segurança pública da Baía de Guanabara é da polícia federal e que deve ser realizada junto da polícia marítima, cabendo à Marinha do Brasil a cooperação nas ações de segurança da região.

Palavras-chave: Intervenção federal; Garantia da lei e da ordem; Segurança pública; Baía de Guanabara; Marinha do Brasil; Polícia federal.

\section{ABSTRACT THE FEDERAL INTERVENTION AND SECURITY RESPONSABILITY IN GUANABARA}

This research focus in analyzing the decrees of Operations of Law and Order Guarantee and Federal Intervention in Rio de Janeiro. In addition, it verifies if the Brazilian Navy must act alone in matters regarding public security in Guanabara Bay and the ports. Therefore, inquiries were made on legal and infralegal apparatuses on the matter, differentiating the Federal Intervention from the Law and Order Guarantee, dealing with the plans provided in MD33-M-10 and the Federal Intervention Plan to understand if the Brazilian Navy possesses police power to do so or is exclusively an Armed Force entitled to act in cooperation with the security forces. Conclusions were drawn indicating that Guanabara Bay's public security is competence of the Federal Police and is to be held with the maritime police. And the Brazilian Navy will be responsible for the cooperation regarding the security actions in the region.

Keywords: Federal Intervention. Law and Order Guarantee. Public Security. Guanabara Bay. Brazilian Navy. Federal Police.

DOI: 10.31060/rbsp.2020.v14.n1.1019

Data de recebimento: 20/10/2018 - Data de aprovação: 30/06/2019 


\section{INTRODUÇÃO}

Este trabalho analisa a situação da segurança pública na Baía de Guanabara (RJ) após a autorização do emprego das Forças Armadas para a garantia da lei e da ordem no estado do Rio de Janeiro, com o decreto de 28 de julho de 2017 e, logo após, com o Decreto n 9.288, de 16 de fevereiro de 2018, que determinou a intervenção federal no estado fluminense. Durante o estudo, analisam-se juridicamente a intervenção federal e as operações de garantia da lei e da ordem, observando-se todo o aparato normativo que autoriza o uso das forças militares, especialmente da Marinha do Brasil, além de adentrar na esfera de competência da Polícia Federal na segurança da Baía de Guanabara. Assim, o objetivo principal do estudo consiste em verificar qual força de segurança possui, atualmente, competência para garantir a fiscalização da baía e do porto, bem como da entrada e saída de embarcações e contêineres, ou se essa competência, hoje, pertence às Forças Armadas. A abordagem será delimitada pela investigação dos diversos aparatos normativos legais e infralegais.

De acordo com declarações apresentadas pelo governador do Rio de Janeiro à época, Luis Fernando Pezão (PMDB), o estado passava por uma intensa crise de segurança pública, com aumentos em todos os índices de violência, o que justificaria, a necessidade da intervenção federal. Esta foi decretada em 2018, pelo presidente Michel Temer, para que as forças de segurança, em conjunto com as Forças Armadas, fossem utilizadas para "pôr termo ao grave comprometimento da ordem pública" no estado. Destaca-se que a Baía de Guanabara é uma das rotas alternativas utilizadas para o transporte de armas e entorpecentes, abastecendo diversas facções criminosas no Rio de Janeiro e fortalecendo o transporte internacional desse tipo de mercadoria. Tal fato já foi denunciado pela Assembleia Legislativa do Rio de Janeiro, por meio da Comissão Parlamentar de Inquérito com a finalidade de investigar "o tráfico de armas, munições e explosivos e a consequente utilização desse arsenal, por traficantes de drogas, milicianos e outros bandidos, quadrilhas ou organizações criminosas", instituída pela Resolução n 19/2011. Reportagens veiculadas nos meios de comunicação de massa também abordaram o tema, como em "Ilhas da Baía de Guanabara são usadas como rotas do tráfico de armas e drogas: tráfico internacional" (DE LIMA; GALDO, 2018).

Durante esta pesquisa, foram formuladas questões sobre se as forças de segurança da Marinha do Brasil atuariam de maneira conjunta com os demais órgãos ou de maneira individual ante o Decreto $n^{\circ} 9.288$, de 16 de fevereiro de 2018. Vale observar que, no início do ano, na assinatura do protocolo para as ações de segurança pública, o Exército ficou incumbido, entre outras medidas, de bloquear rodovias como as BRs 01, 116, 040 e 493, criando postos de revistas, enquanto os planos reservados para a Marinha seriam de fiscalização na Baía de Guanabara e no porto, com o controle de entrada e saída de navios. Além disso, embarcações que ancoram afastadas para esperar a fila do porto e as de passeio e de pesca também seriam alvo de vigilância. Perquire-se sobre qual seria o enquadramento legal possível para esse tipo de fiscalização e qual embasamento normativo para que a Marinha atue sozinha ou em conjunto com as demais forças de segurança.

Mediante a realização de pesquisa exploratória legislativa, levantamento bibliográfico e revisão de literatura, pretende-se analisar a conceituação da intervenção federal e como se dá a operação militar da garantia da lei e da ordem (GLO), em conformidade com: o artigo 142 da Constituição da República Federativa do Brasil; o Decreto 3.897, de 2001, que fixa as diretrizes para o emprego das Forças Armadas nas operações de GLO; a Portaria Normativa n 3.461, que dispõe sobre a garantia da lei e da ordem MD33-M-10 - 1ª Edição/2013 (BRASIL, 2013); os decretos de 28 de julho de 2017 (BRASIL, 2017a, 2017b) 
e o Decreto nº 9.288 (BRASIL, 2018), de 16 de fevereiro de 2018, que vão adentrar a esfera específica da intervenção federal do Rio de Janeiro; o Plano Estratégico da Intervenção Federal, elaborado pelo Gabinete de Intervenção na Segurança Pública do Estado do Rio de Janeiro (GIF/RJ); as normas e procedimentos da Capitania dos Portos do Rio de Janeiro; e por fim a Instrução Normativa $n^{\circ} 2$, de 5 de agosto de 1999, do Departamento de Polícia Federal.

Pretende-se, assim, entender o contexto de competência para a segurança realizada na Baía de Guanabara, ante a recente captura de fuzis e drogas na região da Praia Vermelha, na Urca (RJ), e a responsabilidade de Órgãos de Segurança Pública e das Forças Armadas pela vulnerabilidade na baía.

\section{HIPÓTESSES DE INTERVENÇÃO FEDERAL NA CONSTITUIÇÃO DA REPÚBLICA FEDERATIVAA DO BRASIL (1988)}

A intervenção federal encontra embasamento normativo no Capítulo VI da Constituição Federal de 1988. Vale observar que se trata de ato político que consiste na incursão da entidade interventora nos negócios da entidade que a suporta. Intervenção nada mais é que antítese de autonomia. Com ela, afasta-se momentaneamente a atuação autônoma do estado, Distrito Federal ou município que a tenha sofrido (SILVA, 2014).

O instituto da intervenção vai operar como um garantidor da integridade e do equilíbrio da Federação para além da autonomia que demarca a condição dos seus estados-membros, do Distrito Federal e dos municípios. Apesar de ocasionar uma maior ou menor interferência no ente que sofre a intervenção, ela só irá ocorrer para preservar o interesse maior da União e, consequentemente, dos demais entes federativos (SARLET, 2017).

A intervenção é medida excepcional e só deve ocorrer em casos específicos previstos no aparato normativo da Constituição da República Federativa do Brasil. O artigo 34 é taxativo:

Art. 34. A União não intervirá nos Estados nem no Distrito Federal, exceto para:

I - manter a integridade nacional;

II - repelir invasão estrangeira ou de uma unidade da Federação em outra;

III - pôr termo a grave comprometimento da ordem pública;

IV - garantir o livre exercício de qualquer dos Poderes nas unidades da Federação;

$\checkmark$ - reorganizar as finanças da unidade da Federação que:

a) suspender o pagamento da dívida fundada por mais de dois anos consecutivos, salvo motivo de força maior;

b) deixar de entregar aos municípios receitas tributárias fixadas nesta Constituição, dentro dos prazos estabelecidos em lei;

VI - prover a execução de lei federal, ordem ou decisão judicial;

VII - assegurar a observância dos seguintes princípios constitucionais:

a) forma republicana, sistema representativo e regime democrático;

b) direitos da pessoa humana;

c) autonomia municipal;

d) prestação de contas da administração pública, direta e indireta.

e) aplicação do mínimo exigido da receita resultante de impostos estaduais, compreendida a proveniente de transferências, na manutenção e desenvolvimento do ensino e nas ações e serviços públicos de saúde. (BRASIL, 2000). 
A intervenção federal efetiva-se por decreto do presidente da República, o qual deixará de maneira clara e específica toda a sua abrangência, o seu tempo de duração e as condições para que seja executada, de acordo com o art. $36, \S 1^{\circ}$. Dependendo do tipo de intervenção federal, existe a possibilidade de a figura do interventor não existir. Observa-se que o ato de intervir poderá atingir qualquer órgão do Estado. No caso do estado do Rio de Janeiro, a nomeação de um interventor se fez necessária para o exercício de parte das funções do governador, exclusivamente da pasta da segurança pública, não havendo intervenção em outras áreas do governo.

Ao tratar do controle político, o mesmo ocorre após o decreto ser submetido pelo presidente da República ao Congresso Nacional. O prazo para essa submissão é de 24 horas e, em igual prazo, deverá ser convocado o Congresso de maneira extraordinária, caso não esteja funcionando, para conhecer do ato (art. $\left.36, \S \S 1^{\circ} 2^{\circ}\right)$.

O controle jurisdicional não se aplica no caso de intervenção federal. Há de se observar que o ato de intervenção tem natureza política. A exceção para aplicabilidade do controle jurisdicional ocorre se há infringência às normas constitucionais ou quando a intervenção tenha sido suspensa pelo Congresso Nacional e persista, tendo em vista que, neste último caso, ela perderá legitimidade. O controle jurisdicional, em si, se dá com relação aos atos praticados pelo interventor federal (SILVA, 2014).

Após cessadas as causas que motivaram a intervenção federal, as autoridades que foram afastadas de seu cargo, em regra, retornam. A exceção se dá se ficar constatado algum impedimento legal, conforme art. $36, \S 4^{\circ}$. A intervenção é um ato temporário e a sua duração deve ser estabelecida no decreto assinado pelo presidente da República.

Por fim, verifica-se que a intervenção federal possui uma característica excepcional, prazo limitado e é taxativa, aplicando-se apenas nas hipóteses legais rígidas expressas na Constituição Federal. Na maioria dos casos, ocorre com a nomeação de um interventor federal que possuirá as funções do governador do estado, sendo, portanto, uma medida mais severa do que as operações de garantia da lei e da ordem.

\section{GARANTIA DA LEI E DA ORDEM (GLO)}

As missões de garantia da lei e da ordem (GLO) ocorrem especificamente nos casos em que as forças tradicionais de segurança, como polícia militar, bombeiros e polícia civil, não conseguirem preservar a ordem pública, a integridade da população e o regular funcionamento das instituições. Para que as missões possam ser realizadas, é necessário que o presidente da República, por ordem expressa, embasado pelo art. 142 da Constituição, bem como pela Lei Complementar 97 e pelo Decreto 3.897, de 2001, conceda aos militares, de maneira provisória, a possibilidade de utilizarem o poder de polícia até o restabelecimento da normalidade. Cabe destacar que, diferentemente da intervenção federal, em que existe a figura do interventor, nas operações de garantia da lei e da ordem as Forças Armadas (FA) estão subordinadas ao Secretário de Segurança do Estado.

No Brasil, é possível perceber a intensificação do uso das FA em conjunto com as demais forças de segurança. De acordo com dados do Ministério da Defesa, de 1992 até março de 2019, foram instauradas no Brasil 136 operações de garantia da lei e da ordem. Só no ano de 2017 foram deflagradas oito operações dessa natureza. No Rio de Janeiro, especificamente, o emprego das Forças Armadas aconteceu com o 
decreto de 28 de julho de 2017, com a justificativa do governo estadual no que diz respeito ao aumento exorbitante do número de crimes no estado, especialmente do roubo de cargas nas estradas que cortam o Rio de Janeiro (MINISTÉRIO DA DEFESA, 2020). Todavia, os dados apresentados pelo Instituto de Segurança Pública revelam que os índices de criminalidade, na comparação com os três anos anteriores à intervenção, apresentaram similaridades que não justificariam as declarações dos representantes do governo estadual fluminense (INSTITUTO DE SEGURANÇA PÚBLICA, 2020).

Vale observar que a atuação das Forças Armadas nas atividades de segurança pública não descaracteriza sua natureza militar. Assim, na hipótese de alguma violação legal por parte dos agentes militares que estiverem executando determinada operação, a competência será da Justiça Militar, e não da Justiça Comum, exatamente de acordo com o art. 15, § $7^{\circ}$ da Lei Complementar 97, de 1999. Além do mais, a partir da Lei $n^{\circ}$ 13.491, de 2017, a competência para julgamento e processamento dos crimes de militares contra civis, que antes era da Justiça Comum, passou a ser regulamentado pela Justiça Militar (BRASIL, 2017).

\section{DECRETO DE 28 DE JULHO DE 2017 E O PLANO NACIONAL DE SEGURANÇA PÚBLICA}

O Decreto de 28 de julho de 2017 foi o décimo a autorizar, no Rio de Janeiro, o emprego das Forças Armadas para a garantia da lei e da ordem por motivos de violência urbana. De acordo com o texto legal, ante a imensa situação de calamidade, especificamente na segurança pública do Estado do Rio de Janeiro, autorizou-se que as Forças Armadas dessem apoio às ações do Plano Nacional de Segurança Pública.

Cabe esclarecer que o Plano Nacional proposto em 2017 tinha como objetivo trabalhar de forma integrada com todas as esferas do poder público, não apenas com o Executivo, Legislativo e Judiciário. A União teria uma integração com todos os entes federativos objetivando melhorar a segurança no país. Assim, ainda em 2017, o Rio de Janeiro foi o primeiro estado a receber ações do Plano Nacional de Segurança Pública, apresentando três principais objetivos: redução de homicídios dolosos, feminicídios e casos de violência contra a mulher; racionalização e modernização do sistema penitenciário; e combate integrado à criminalidade organizada transnacional. Como metas, foram apresentadas as seguintes: para os homicídios dolosos, redução anual de 7,5\% nos municípios abrangidos pelo plano. No combate à violência doméstica, aumento e celeridade das investigações e dos processos. No que diz respeito ao sistema penitenciário, trazer informações completas e detalhadas em tempo real de todo o sistema e, por fim, aumento na quantidade de apreensão de armas e drogas, para o combate ao crime organizado (BRASIL, 2017a).

\section{MANUAL MD33-M-10}

Objetivando aplicar de maneira mais contundente as missões de GLO, foi elaborado o Manual MD33-M-10, aprovado pela Portaria Normativa 3.461/2013, do Ministério da Defesa e atualizado em 2014 com a Portaria Normativa 186. O referido manual estabelece orientações para o planejamento e o emprego das Forças Armadas em operações de garantia da lei e da ordem, conceituadas como:

Operação de Garantia da Lei e da Ordem (Op GLO) é uma operação militar determinada pelo Presidente da República e conduzida pelas Forças Armadas de forma episódica, em área previamente estabelecida e por tempo limitado, que tem por objetivo a preservação da ordem pública e da incolumidade das pessoas e do patrimônio em situações de esgotamento dos 
instrumentos para isso previstos no art. 144 da Constituição ou em outras em que se presuma ser possível a perturbação da ordem. (Artigos $3^{\circ}, 4^{\circ}$ e $5^{\circ}$ do Decreto $n^{\circ} 3.897$, de 24 de agosto de 2001). (BRASIL, 2014).

Ainda de acordo com o MD33-M-10, as operações de garantia da lei e da ordem objetivam uma atuação de forma integrada. Ou seja, o planejamento e a execução dessas operações contemplam a possibilidade de participação das Forças Armadas, dos órgãos de segurança pública, do Poder Executivo, do Poder Judiciário, do Ministério Público e de outros órgãos ou agências afins e de interesse da operação. No planejamento, tanto o conhecimento quanto a experiência dos diversos órgãos de segurança pública devem ser explorados. No que tange às ações, os órgãos com vocação para a atividade em questão devem ter prioridade de emprego.

Especificamente no que diz respeito à Marinha do Brasil, o Manual entende que ela pode realizar diversas ações de segurança. Entre elas, destaca-se a ação de proteção aos portos, seus acessos e fundeadouros, estaleiros ou águas marítimas restritas.

Assim, as operações de garantia da lei e da ordem ocorrem apenas nos casos específicos elencados na lei. Diferentemente da intervenção federal, elas mantêm a gestão de segurança nas mãos do secretário estadual de segurança, e não nas mãos do interventor federal. Cabe destacar, ainda, que com a Intervenção na pasta de Segurança Pública, o secretário de segurança pública ficou hierarquicamente vinculado ao interventor, e não mais ao governador. Certo é que, assim como para a intervenção federal, há necessidade de autorização expressa pelo presidente da República para que seja aplicada. No que tange às ações dessas operações, o MD33-M-10 entende a necessidade de uma cooperação das FA com todas as forças de segurança. Salienta-se, ainda, que a prioridade nas operações é dos órgãos com vocação para tal ato. No que diz respeito à Marinha do Brasil, ela tem poder, mas não é obrigada a realizar ações de segurança, principalmente no que diz respeito à proteção dos portos e seus acessos.

\section{INTERVENÇÃO FEDERAL NO RIO DE JANEIRO}

\section{DECRETO N 9.288, DE 16 DE FEVEREIRO DE 2018}

O Decreto n 9.288, de 16 de fevereiro de 2018, determinou a intervenção federal do estado do Rio de Janeiro. Seu objetivo era exclusivamente pôr fim ao grave comprometimento da ordem pública no estado fluminense (BRASIL, 2018). A intervenção federal tem prazo determinado. De acordo com o art. $1^{\circ}$ do referido decreto, a data de encerramento é 31 de dezembro de 2018. Além do mais, é importante salientar que a intervenção limita-se à área de segurança pública.

O decreto estabelece que o cargo de interventor federal é de natureza militar, sendo nomeado o general do Exército Walter Souza Braga Netto. A natureza militar do interventor foi definida pelo decreto e não por força da Constituição Federal. Vale destacar que o interventor subordina-se ao presidente da República, não estando sujeito a qualquer norma estadual que conflite com as medidas necessárias para a consecução da intervenção.

O interventor tem a possibilidade de requisitar os meios necessários para o objetivo da intervenção a quaisquer órgãos, sejam civis sejam militares, da administração pública federal. E, pode, ainda, solicitar, durante o período de intervenção, os bens, serviços e servidores das áreas da Secretaria de Segurança, da 
Secretaria de Administração Penitenciária e do Corpo de Bombeiros Militar do estado do Rio de Janeiro, para emprego nas ações de segurança pública.

\section{PLANO ESTRATÉGICO DA INTERVENÇÃO FEDERAL (PORTARIA NORMATIVA Nº 5/GABINETE DE INTERVENÇÃO FEDERAL, DE 29 DE MAIO DE 2018)}

O Gabinete de Intervenção Federal na Segurança Pública do Estado do Rio de Janeiro (GIF/RJ), para garantir maior efetividade nas suas ações, aprovou o Plano Estratégico da Intervenção Federal na Área da Segurança Pública do Estado do Rio de Janeiro (GIF, 2018). Sua finalidade é estabelecer as bases do planejamento estratégico e de gestão das atividades a serem desenvolvidas no âmbito do GIF/RJ. Em um viés político, salienta que o interventor é equivalente ao governador do estado para todos os assuntos referentes à segurança pública, respondendo diretamente ao presidente da República.

O nível estratégico da intervenção federal compõe-se pelo Gabinete de Intervenção Federal e pelo Comando Militar do Leste, com ligação estreita com os Ministérios da Defesa e Extraordinário da Segurança Pública e com o Gabinete de Segurança Institucional da Presidência da República. Eles são responsáveis pela coordenação e integração das ações que viabilizam a intervenção federal. Todos os objetivos, estratégias, metas e ações estabelecidos no plano estratégico coordenam-se com o Comando Conjunto e as secretarias de governo do estado, atuando de forma integrada a elas (BRASIL, 2018).

A Polícia Federal, a Polícia Rodoviária Federal, a Força de Segurança Pública e a Agência Brasileira de Inteligência compõem, com o Comando Conjunto e as secretarias do governo estadual, o elemento operacional da intervenção federal. Vale observar que este possui uma forte característica interagências nas esferas municipal, estadual e federal. O elemento tático, por sua vez, é composto pelas tropas federais das Forças Armadas, que estão adjudicadas ao Comando Conjunto, e pelos órgãos de segurança pública do estado do Rio de Janeiro, ou seja, a polícia militar, a polícia civil e o corpo de bombeiros.

Todas as atividades de segurança pública, administração penitenciária e de defesa civil têm planejamento e efetividade atribuídos às suas respectivas secretarias, por meio dos órgãos de segurança pública e demais instituições. E, sempre que necessário, atuam em conjunto, com a cooperação das Forças Armadas, que já foram empregadas nas ações de garantia da lei e da ordem com o decreto publicado em 27 de julho de 2017. Todas as atividades são executadas nos eixos de segurança pública e de defesa.

O eixo da segurança pública compreende as atividades da polícia federal, polícia rodoviária federal, polícia civil, polícia militar, corpo de bombeiros e guarda municipal. Verifica-se que as atividades contempladas são de ações de polícia ostensiva, preservação da ordem pública e ordenamento urbano, segurança viária e controle de tráfego, segurança de infraestruturas críticas, polícia judiciária, polícia marítima, aeroportuária e de fronteiras, inteligência e polícia civil.

Já no eixo da defesa, as atividades são desenvolvidas pelo Comando Conjunto das Forças Armadas, especialmente para as ações de garantia da lei e da ordem no estado do Rio de Janeiro, sendo contempladas operações aéreas, ações marítimas e fluviais, ações de transporte aéreo logístico, fiscalização de produtos controlados, proteção de estruturas estratégicas, policiamento ostensivo sempre em reforço aos órgãos de segurança pública, operações especiais com tropas especializadas das Forças Armadas e dos órgãos de segurança pública e de assistência militar. 
Em síntese, de acordo com o Plano Estratégico da Intervenção Federal, não há que se falar em poder de polícia das Forças Armadas. Trata-se única e exclusivamente de um eixo de defesa que objetiva trabalhar de maneira cooperativa e como reforço aos demais órgãos de segurança pública do estado do Rio de Janeiro, deixando-se bem claro que o eixo de segurança pública destina-se às atividades da polícia federal, polícia rodoviária federal, polícia civil, polícia militar, corpo de bombeiros e guarda municipal.

\section{ÓRGÃOS DE SEGURANÇA PÚBLICA E POLÍCIA MARÍTIMA}

A Constituição da República Federativa do Brasil expõe no seu artigo 144, com detalhamento, quais são os órgãos de segurança pública. Para tanto, elenca em cada um dos seus incisos, respectivamente, que a polícia federal, a polícia rodoviária federal, a polícia ferroviária federal, as polícias civis, as polícias militares e o corpo de bombeiros militares são as forças de segurança pública que exercem, respeitadas as competências privativas e exclusivas de cada uma, as funções de polícia judiciária e de polícia ostensiva (BRASIL, 1988).

Verifica-se que a atividade policial, seja ela de polícia ostensiva seja judiciária, é elencada no artigo 144. Assim, considerando que o $\S 1^{\circ}$ determina que a polícia federal não é destinada apenas para as funções de polícia judiciária da União, entende-se que ela também tem atribuição de atividade de polícia marítima, aeroportuária e de fronteiras (BRASIL, 1988). Nesse sentido, no que tange à repressão de ilícitos praticados a bordo, como a repressão ao tráfico de drogas, contrabando e descaminho, de acordo com a Constituição de 1988, a atividade é de competência da polícia federal.

\section{NORMAS E PROCEDIMENTOS DA CAPITANIA DOS PORTOS}

As Normas e Procedimentos para a Capitania dos Portos do Rio de Janeiro (NPCP), no seu capítulo 3, ao tratarem de procedimentos para navios no porto, estabelecem na Seção IV, segurança, que a autoridade competente para investigar e coibir ilícitos penais a bordo de embarcações, de acordo com a legislação vigente, é a polícia marítima, aérea e de fronteiras, que é exercida exclusivamente pela polícia federal.

\section{DEPARTAMENTO DE POLÍCIA FEDERAL (INSTRUÇÃO NORMATIVA N², DE 5 DE AGOSTO DE 1999)}

Nesse esteio, o departamento de polícia federal, por meio da Instrução Normativa $n^{\circ} 2$, de 5 de agosto de 1999, disciplina toda a organização e o funcionamento das atividades dos Núcleos Especiais de Polícia Marítima (Nepom), além de estabelecer suas competências e atribuições:

Considera-se Polícia Marítima a atividade de competência privativa do Departamento de Polícia Federal, exercida por seus servidores policiais, em âmbito nacional, pelo SERVIÇO POLícIA MARÍTIMA, AEROPORTUÁRIA E DE FRONTEIRAS da DPMAF e, regionalmente, por intermédio de suas Unidades de Polícia Marítima, com atuação nos portos e mar territorial brasileiro, objetivando principalmente a prevenção e a repressão aos ilícitos praticados a bordo, contra ou em relação a embarcações na costa brasileira, e a fiscalização do fluxo migratório no Brasil (entrada e saída de pessoas), sem prejuízo da prevenção e repressão aos demais ilícitos de competência do DPF, inclusive estendendo-se além do limite territorial, quando se fizer necessário e observadas as normas específicas da Marinha do Brasil. (DEPARTAMENTO DE POLíCIA FEDERAL, 1999, p. 1). 
Além do mais, ainda se compreendem como atividades de polícia marítima as providências ou medidas que devam ser implementadas nos portos, terminais e vias navegáveis, objetivando manter a segurança, quando não constituam atribuições específicas da polícia civil, polícia militar ou das Forças Armadas.

Cabe ressaltar que, entre as competências da polícia marítima presentes no art. $7^{\circ}$ da Instrução Normativa $n^{\circ} 5$, constam especificamente a prevenção e repressão dos crimes de competência do departamento de polícia federal praticados na área portuária, em suas adjacências e no mar territorial brasileiro, incluindo o tráfico de armas de fogo, de pessoas, armas químicas, nucleares, biológicas e congêneres; o terrorismo por via aquática; e outros crimes praticados no âmbito marítimo que tenham repercussão interestadual ou internacional e que exijam repressão uniforme. A IN n ${ }^{\circ} 5$ trata ainda da expedição de passe de entrada e de saída para embarcações fiscalizadas em cada porto e do policiamento da área portuária, mediante o patrulhamento sistemático marítimo e terrestre (BRASIL, 1999).

Assim, verifica-se que entre os órgãos de segurança pública elencados no art. 144 da Constituição, cabe à polícia federal realizar, através da polícia marítima, todo o patrulhamento e segurança no que tange ao deslocamento de entorpecentes e armas na Baía de Guanabara.

\section{CONSIDERAÇÕES FINAIS}

A intervenção federal é excepcional, possui prazo predeterminado e se aplica nas hipóteses taxativas previstas na Constituição Federal. Nem sempre existe o interventor federal, mas, na maioria das hipóteses conhecidas, essa figura se faz presente substituindo as funções de governador do estado que está sofrendo a intervenção. Trata-se, evidentemente, de uma medida mais severa que as missões de garantia da lei e da ordem.

Verificou-se também que a as operações de garantia da lei e da ordem dependem da autorização expressa do presidente da República. Além do mais, diferentemente da intervenção federal, as operações de GLO mantêm nas mãos do secretário estadual de segurança, e não nas do interventor federal, a gestão da segurança pública.

No que tange às operações de GLO, verificou-se a existência de um manual conhecido como MD33-M-10, que determina a cooperação das Forças Armadas com todas as forças de segurança. Além do mais, destacou-se que a prioridade nas operações é dos órgãos que possuem vocação para tal ato. No que diz respeito especificamente à Marinha do Brasil, entendeu-se que ela possui poder para atuar na proteção dos portos e seus acessos, mas não possui dever para tanto.

Com relação ao plano estratégico da intervenção federal, elaborado pelo gabinete de intervenção federal do Rio de Janeiro, não há que se falar de um poder de polícia das Forças Armadas. Estas são consideradas um eixo de defesa que tem como objetivo trabalhar de forma a reforçar os demais órgãos de segurança e cooperar com eles. Estabelece-se, de maneira clara, que o eixo de segurança pública é destinado às atividades das polícias federal, rodoviária federal, civil, militar, do corpo de bombeiros e da guarda municipal.

Por fim, de acordo com o artigo 144 da Constituição da República Federativa do Brasil, a competência da segurança pública na Baía de Guanabara é da Polícia federal, realizada por meio da polícia marítima, que deve manter o patrulhamento e a segurança da região. 


\section{REFERÊNCIAS BIBLIOGRÁFICAS}

BONAVIDES, Paulo. Curso de Direito Constitucional. 27ª ed. Atual. - São Paulo: Malheiros Editores, 2012.

BRASIL. Constituição da República Federativa do Brasil. Brasília, DF: Senado Federal: 1988.

BRASIL. Decreto de 28 de julho de 2017. Autoriza o emprego das Forças Armadas para a Garantia da Lei e da Ordem no Estado do Rio de Janeiro. Brasília, DF: jul 2017 b.

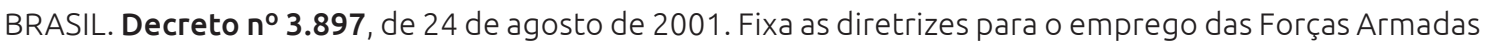
na garantia da lei e da ordem, e dá outras providências. Brasília, DF: ago. 2001.

BRASIL. Decreto n 9.288, de 16 de fevereiro de 2018. Decreta intervenção federal no Estado do Rio de Janeiro com objetivo de pôr termo ao grave comprometimento da ordem pública. Brasília, DF: fev 2018.

BRASIL. Emenda Constitucional n²9, de 13 de setembro de 2000. Altera os arts. 34, 35, 156, 160, 167 e 198 da Constituição Federal e acrescenta artigo ao Ato das Disposições Constitucionais Transitórias, para assegurar os recursos mínimos para o financiamento das ações e serviços públicos de saúde. Brasília, DF, 13 set. 2000.

BRASIL. Lei Complementar n97, de 9 de junho de 1999. Dispõe sobre as normas gerais para a organização, o preparo e o emprego das Forças Armadas. Brasília, DF: jun 1999.

BRASIL. Plano Nacional de Segurança Pública: 2017. Brasília, DF: 2017a. Disponível em: <http://www. justica.gov.br/noticias/plano-nacional-de-seguranca-preve-integracao-en-tre-poder-publico-e-sociedade/ pnsp-06jan17.pdf>. Acesso em: 15 mar. 2018.

BRASIL. Portaria Normativa n³.461/MD, de 19 de dezembro de 2013. Dispõe sobre a publicação "Garantia da Lei e da Ordem". Brasília, DF: dez 2013.

BRASIL. Portaria Normativa n 186/MD, de 31 de janeiro de 2014. Dispõe sobre a publicação "Garantia da Lei e da Ordem". Brasília, DF: dez 2014.

CÂMARA, Heloísa Fernandes; MOREIRA. Egon Bockmann. Intervenção Federal: existe algo de jurídico neste ato político? Disponível em: . Acesso em: 10.ago.2018

CAPITANIA DOS PORTOS DO RIO DE JANEIRO. Normas e procedimentos. Disponível em: "https://www. marinha.mil.br/cprj/npcp"; Acesso em 10/agosto/2018.

DE LIMA, Ludmilla; GALDO, Rafael. Ithas da Baía de Guanabara são usadas como rotas do tráfico de armas e drogas. O Globo. 28 out. 2018. Disponível em: <https://oglobo.globo.com/rio/ilhas-da-baia-deguanabara-sao-usadas-como-rotas-do-trafico-de-armas-drogas-23191898>. Acesso em 12 de nov. 2019.

DEPARTAMENTO DE POLÍCIA FEDERAL. Instrução Normativa No 2, de 5 de agosto de 1999. Disponível em: "https://www.dpc.mar.mil.br/sites/default/files/ssta/legislacao/inst_normativa/inst_norm2.pdf"; Acesso em 10/agosto/2018.

GIF. Gabinete de Intervenção Federal. Brasil. Portaria Normativa nº 5, de 29 de maio de 2018. Aprova o Plano Estratégico da. Intervenção Federal na Área da Segurança Pública do Estado do Rio de Janeiro. Rio de Janeiro: GIF, maio 2018.

GODOY, Marcelo. Forças Armadas vão atuar para deter entrada de drogas e armas no Rio. O Estado de São Paulo. 21 fev. 2018. Disponivel em: <https://brasil.estadao.com.br/noticias/rio-de-janeiro,forcasarmadas-vao-atuar-para-deter-entrada-de-drogas-e-armas-no-rio,70002197516>. Acesso em 12 ago. 2018 
INSTITUTO DE SEGURANÇA PÚBLICA. Secretaria de Estado de Segurança Pública (2020). Estatísticas de segurança: série histórica anual no estado desde 1991 (taxas por 100 mil habitantes). Disponível em < http://www.ispdados.rj.gov.br/Arquivos/DOMensalEstadoDesde1991TAXA.csv> Acesso em: 15 mai. 2020.

GOVERNO Federal e Rio assinam protocolo para ações de segurança pública. Ministério da Defesa. 12 jan. 2018. Disponível em: <https://www.defesa.gov.br/noticias/38609-governo-federal-e-rio-assinamprotocolo-para-acoes-de-seguranca-publica>. Acesso em: 22 ago. 2018

LENZA, Pedro. Direito Constitucional Esquematizado. 18. ed. São Paulo: Saraiva, 2014.

MACEDO, Aline; TEIXEIRA, Fábio. Índices de violência sobem no Estado do Rio. O Globo. 17 fev. 2018. Disponivel em: <https://oglobo.globo.com/rio/indices-de-violencia-sobem-no-estado-do-rio-22407369>. Acesso em: Acesso em 22 ago. 2018

MINISTÉRIO DA DEFESA. Chefia de operações conjuntas. Subchefia de operações. Seção de operações complementares. Histórico de GLO. Brasília, DF: mar 2020. Disponível em: <https://www.defesa.gov.br/arquivos/ exercicios_e_operacoes/glo/2.TABELAS_GLO_atualizada_em_MAR_20.pdf>. Acessado em: 15 mai. 2020.

NOVELINO, Marcelo. Curso de Direito Constitucional. 12ªed. - revista, atualizada e ampliada. Salvador: JusPODIVM, 2017.

OUCHANA, Giselle; GOULART, Gustavo. Órgãos de segurança não se entendem sobre policiamento na Baía de Guanabara. O Globo. 14 jun. 2018. Disponível em: <https://oglobo.globo.com/rio/orgaos-deseguranca-nao-se-entendem-sobre-policiamento-na-baia-de-guanabara-22773485\#ixzz5QeqAP5Y3>. Acesso em: 22 ago. 2018

RIO DE JANEIRO registra, em média, 23 roubos de carga por dia; frequência de casos encarece preços de diversos produtos. Bom Dia Rio. 16 jan. 2018. Disponível em: <https://g1.globo.com/rj/rio-de-janeiro/ noticia/rj-registra-em-media-23-roubos-de-carga-por-dia-frequencia-de-casos-encarece-precos-dediversos-produtos.ghtml>. Acesso em 09 set. 2018.

RIO DE JANEIRO. Assembléia Legislativa do Estado - ALERJ. Comissão Parlamentar de Inquérito (Resolução no 19/2011). Relatório final da CPI com a finalidade de investigar, no âmbito do Estado do Rio de Janeiro, o tráfico de armas, munições e explosivos e a conseqüente utilização desse arsenal, por traficantes de drogas, milicianos e outros bandos, quadrilhas ou organizações criminosas. Disponível em: <https://docplayer.com.br/259466-Assembleia-legislativa-do-estado-do-rio-de-janeiro-relatorio-final. html>. Acesso em 12 nov. 2019.

SARLET, Ingo Wolfgang; MARINONI, Luiz Guilherme; MITIDIERO, Daniel. . Curso de direito constitucional. / Ingo Wolfgang Sarlet, Luiz Guilherme Marinoni e Daniel Mitidiero. - 6. ed. - São Paulo: Saraiva, 2017.

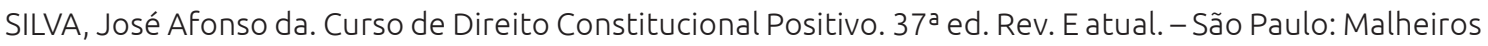
Editores, 2014. 
A intervenção federal e a responsabilidade da segurança pública na Baía de Guanabara

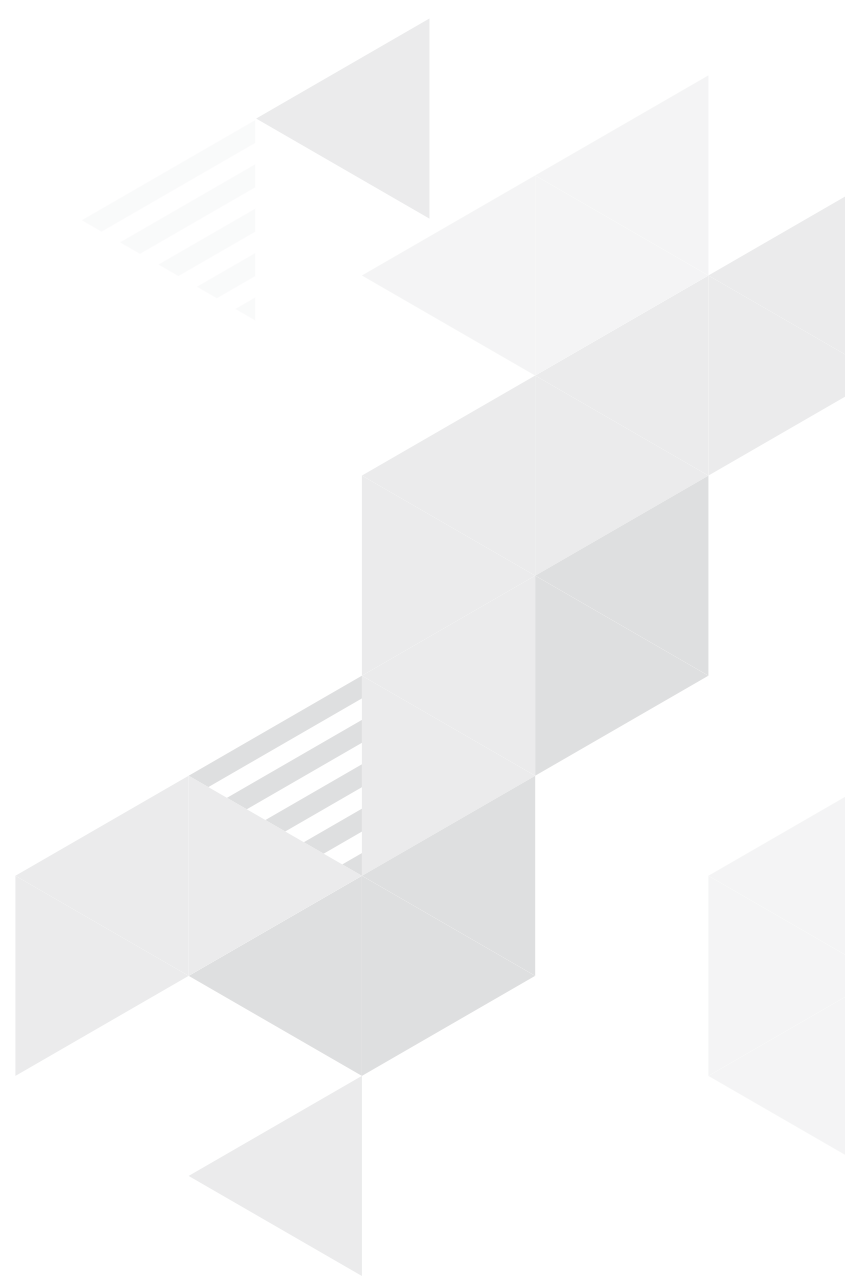

